\title{
The spliceosome factor sart3 regulates hematopoietic stem/ progenitor cell development in zebrafish through the p53 pathway
}

\author{
Yan Zhao $\mathbb{D}^{1,2,5}$, Mei Wu $\mathbb{D}^{1,5}$, Jing $\mathrm{Li}^{1}$, Ping Meng ${ }^{3}$, Jiakui Chen ${ }^{3}$, Zhibin Huang ${ }^{1}$, Jin Xu $\mathbb{D}^{1}{ }^{1}$, Zilong Wen ${ }^{4}$, Wenqing Zhang ${ }^{1}{ }^{\circledR}$ and \\ Yiyue Zhang (iD) ${ }^{1 凶}$
}

(c) The Author(s) 2021

\begin{abstract}
Hematopoietic stem cells (HSCs) possess the potential for self-renew and the capacity, throughout life, to differentiate into all blood cell lineages. Yet, the mechanistic basis for HSC development remains largely unknown. In this study, we characterized a zebrafish smu471 mutant with hematopoietic stem/progenitor cell (HSPC) defects and found that sart3 was the causative gene. RNA expression profiling of the sart $3^{\text {smu471 }}$ mutant revealed spliceosome and p53 signaling pathway to be the most significantly enriched pathways in the sart $3^{\text {smu }} 471$ mutant. Knock down of $p 53$ rescued HSPC development in the sart $3^{\text {smu471 }}$ mutant. Interestingly, the p53 inhibitor, $m d m 4$, had undergone an alternative splicing event in the mutant. Restoration of $m d m 4$ partially rescued HSPC deficiency. Thus, our data suggest that HSPC proliferation and maintenance require sart3 to ensure the correct splicing and expression of $m d m 4$, so that the p53 pathway is properly inhibited to prevent definitive hematopoiesis failure. This study expands our knowledge of the regulatory mechanisms that impact HSPC development and sheds light on the mechanistic basis and potential therapeutic use of sart3 in spliceosome-mdm4-p53 related disorders.
\end{abstract}

Cell Death and Disease (2021)12:906; https://doi.org/10.1038/s41419-021-04215-4

\section{INTRODUCTION}

Hematopoiesis is tightly regulated by multidimensional pathways [1-3], with dysregulation resulting in anemia, leukemia, and other hematological diseases $[4,5]$. Blood development in vertebrates is comprised of primitive and definitive waves [6]. In mammals, the first hematopoietic wave takes place in the yolk sac and gives rise to primitive erythrocytes and macrophages that support tissue oxygenation and immune defense during early embryonic development [1, 7]. Primitive hematopoiesis is transitory and followed by definitive hematopoiesis, which includes yolk sacderived erythroid-myeloid progenitors. These progenitors contribute to the intermediate wave [8], with later hematopoietic stem cells (HSCs) contributing to hematopoiesis throughout life [9]. Definitive HSCs, which can give rise to all blood lineages, originate from an endothelial-to-hematopoietic transition process within the aorta-gonad mesonephros (AGM) region [10, 11]. These cells migrate to the fetal liver and colonize bone marrow (BM), where they maintain adult hematopoiesis $[12,13]$. Similarly, zebrafish hematopoiesis is also comprised of a first primitive wave, a transient erythroid-myeloid progenitor wave, and a definitive HSC contributed wave [14]. HSCs emerge from the ventral wall of the dorsal aorta (VDA, equivalent to the mammalian AGM) and enter the circulation after initiation of the endothelial-to-hematopoietic transition process $[15,16]$. The cells colonize the caudal hematopoietic tissue ( $\mathrm{CHT}$, equivalent to the mammalian fetal liver) [17, 18], then migrate to adult hematopoietic organs, which include the thymus as well as kidney marrow (equivalent to the mammalian BM) [1]. As HSCs are the apex of the blood hierarchy and have the potential to selfrenew and differentiate into all blood cell lineages [19, 20], analysis of HSC biology is essential for a better understanding of hematopoiesis and the treatment of blood disorders.

In the past few decades, spliceosome genes most frequently involved in hematopoiesis and leukemogenesis have been identified including; U2AF1, SF3B1, and SRSF2 [21-23]. Mice with the U2AF1 (S34F) mutation exhibit a defect in hematopoiesis as well as an alteration in pre-mRNA splicing in BM progenitors [24]. Mice bearing the $S f 3 b 1^{\mathrm{K} 700 \mathrm{E}}$ mutation exhibit decreased numbers of mature erythrocytes and long-term HSC expansion [25]. Mice bearing the Srsf2P95H mutation have key hematopoietic regulator splicing mistakes as well as impaired hematopoietic differentiation [26]. These mutations occur in myelodysplastic syndrome, chronic myelomonocytic leukemia, and acute myeloid leukemia, which can also be used as prognostic biomarkers of disease [22, 23]. Moreover, several studies have shown these spliceosome genes (such as SF3B1) to be potential antitumor targets [25, 27-29].

\footnotetext{
'Division of Cell, Developmental and Integrative Biology, School of Medicine, South China University of Technology, Guangzhou 510006, P.R. China. ${ }^{2}$ School of Biology and Biological Engineering, South China University of Technology, Guangzhou 510006, P.R. China. ${ }^{3}$ Department of Developmental Biology, School of Basic Medical Sciences, Southern

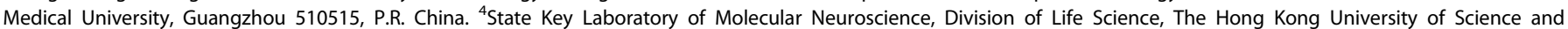
Technology, Hong Kong, P.R. China. ${ }^{5}$ These authors contributed equally: Yan Zhao, Mei Wu. ${ }^{\varpi_{e}}{ }$ ail: mczhangwq@scut.edu.cn; mczhangyy@scut.edu.cn Edited by Anastasis Stephanou
}

Received: 5 July 2021 Revised: 9 September 2021 Accepted: 23 September 2021

Published online: 05 October 2021 
Therefore, exploring novel spliceosome genes and their role in hematopoiesis will benefit the development of new therapeutic strategies for treatment of blood diseases.

Squamous cell carcinoma antigen recognized by $\mathrm{T}$ cells 3 (SART3), also known as p110/p110 nrb [30] or TIP110 [31], is a homolog of yeast spliceosome recycling factor Prp24 [32] and an RNA-binding protein [30]. Similar to yeast Prp24, mammalian SART3 likely reassembles U4/U6 small nuclear ribonucleoproteins (snRNPs), affecting pre-mRNA splicing by binding to U6 snRNP [32-34]. Moreover, SART3 is multifunctional with involvement in gene regulation [35-37], cancer immunology [38-40], stem cell pluripotency maintenance [41, 42], embryonic development [43], and hematopoiesis [36, 43, 44]. During BM hematopoiesis, Sart3 haplo-insufficient mice exhibit decreased numbers of hematopoietic progenitor cells (HPCs) and SART3 transgenic mice exhibit increased HPCs, likely due to cell cycle regulation mediated by CMYC [36]. Trede et al. reported a zebrafish sart3 mutant with a lymphoid cell deficiency but normal levels of primitive erythrocytes [43], supporting sart3 involvement in hematopoiesis. However, the role of SART3, in early hematopoietic stem/ progenitor cell (HSPC) development, is largely undefined.

In this study, we characterized a zebrafish sart $3^{\text {smu471 }}$ mutation, which resulted in a deficiency of HSPC development largely due to activation of the p53 pathway. Moreover, we found that sart3 mutation-induced global splicing changes that included alternative splicing (AS) of $m d m 4$, one key p53 negative regulator, which triggered p53 activation, impacting HSPC proliferation and maintenance. Taken together, this study identifies a novel role for splicing factor and sart3 in regulation of early HSPC development.

\section{RESULTS}

\section{The smu471 mutant is defective in HSPC development}

To explore novel genes and pathways involved in definitive hematopoiesis, we previously performed an N-ethyl-N-nitrosourea-based large-scale forward genetics screening to identify mutants with hematopoietic defects [45]. One of the mutants, smu471, did not display the erythroid marker (ße1-globin) or the lymphoid marker (rag1) at 5 days post fertilization (dpf), but the HSPC marker (cmyb) was observed at $36 \mathrm{~h}$ post fertilization (hpf) [45] (Fig. S1). Next, primitive hematopoiesis was examined. The erythrocyte progenitor marker gata1 (Fig. S2A) and the myeloid progenitor marker pu.1 (Fig. S2B, C) were intact, suggesting that primitive hematopoiesis was unaffected by the mutation. Since definitive HSPCs can differentiate into all blood lineages, both 5-dpf erythroid and lymphoid disruption in smu471 prompted us to speculate that HSPCs were likely defective in the mutant. HSPCs are generated from the VDA $30 \mathrm{hpf}[15,16]$ and then migrate, differentiate, and expand in the CHT $[1,17,18]$. We therefore examined the HSPCs in the respective regions for HSPC marker (cmyb, runx 1, and gata2b) expression at $36 \mathrm{hpf}$ and $2 \mathrm{dpf}$ in the smu471 mutant. The results showed that cmyb- (Fig. $1 \mathrm{~A}$ and Fig. S1C), runx1- (Fig. S3A, B), and gata2b- (Fig. S3C, D) marked HSPCs in the VDA region, were similar to siblings of the smu471 mutant. Notably, cmyb expression was detected at $2.5 \mathrm{dpf}$ (Fig. 1B), $3 \mathrm{dpf}$ (Fig. 1C), and $4 \mathrm{dpf}$ (Fig. 1D) in the CHT region but was obviously decreased in the smu471 mutant from $2.5 \mathrm{dpf}$ onward. Since the $T g(c d 41: e G F P)$ transgenic fish line labels developing HSPCs in the VDA and CHT region, with eGFPlow cells as HSPCs and eGFPhigh cells as thrombocytes [46], we monitored VDA and CHT region HSPC number using the inter-crossed progenies of the sart $3^{+/ s m u 471} ; \mathrm{Tg}(\mathrm{cd} 41: \mathrm{eGFP})^{+/+}$transgenic zebrafish. The results showed that the cd41:eGFPlow cells were intact at $2 \mathrm{dpf}$ in the VDA and CHT region, but were decreased from 2.5 to $4 \mathrm{dpf}$ in the $\mathrm{CHT}$ region in smu471 mutants compared with their siblings (Fig. S4A-G), which were consistent with the WISH expression of runx 1, gata2b, and cmyb. Moreover, we found the proportion of cd41:eGFPlow cell population at $4 \mathrm{dpf}$ in smu471 mutants was markedly decreased compared with their siblings using Fluorescence-activated cell sorting (FACS) (Fig. S4H, I). These results suggest that HSPCs arise normally from the VDA region whereas CHT localized HSPCs are affected in the smu471 mutant.

\section{Sart3 is the causative gene of the smu471 mutation}

To identify the causative gene responsible for the defective HSPCs of the smu471 mutant, we performed positional cloning. We located the mutant gene on chromosome 5 by initial mapping. Next, we used fine mapping to identify the candidate interval between two simple sequence length polymorphism (SSLP) markers: z20360 and z21082, which contained 20 candidate genes (Fig. 2A). By sequencing the cDNA of these candidate genes, we found a $T$ to $A$ base substitution at sart3 exon 6 , which encoded a stop codon (Fig. 2B). The nonsense mutation predicted a truncated Sart3 protein lacking its RNA recognition motif (RRM) domain (Fig. 2C).

To confirm sart3 as the causative gene of the smu471 mutant, we performed a rescue experiment by overexpressing zebrafish sart3 mRNA in smu471 mutant embryos. Zebrafish sart3 mRNA recovered cmyb and rag1 expression of the smu471 mutant (Fig. 2D, S5A). Furthermore, human SART3 mRNA also rescued the hematopoietic defect of the smu471 mutant (Fig. S5B), suggesting functional conservation across species. Notably, we generated another sart3 mutant zebrafish by CRISPR/Cas9, which had 14-base pairs deleted and 4-base pairs added in exon 1, identified as $\operatorname{sart}^{(\Delta 14,+4)}$ (Fig. 2E). The mutant predictably generated a premature Sart3 protein (Fig. 2F) that exhibited the same phenotype as the smu471 mutant (Fig. 2G). Moreover, we outcrossed heterozygous smu471 with heterozygous sart $3^{+/(\Delta 14,+4)}$ producing a bi-allelic mutant sart3 $^{(\Delta 14,+4) / s m u 471}$, which had a similar HSPC defect as the smu471 mutant (Fig. 2H). Taken together, these data indicate that sart3 is the causative gene of the smu471 mutant zebrafish (named sart $3^{\text {smu471 }}$ hereafter).

HSPCs undergo arrested proliferation and increased apoptosis in the sart3 $3^{\text {smu471 }}$ mutant

Based on the published time-series RNA-seq data of the zebrafish $\mathrm{CHT}$ region [47] (http://www.picb.ac.cn/hanlab/ichtatlas/Home/), we found the dynamic expression of sart3 to gradually increase with HSPC developmental stage. The sart 3 expression in HSPC was low at HSPC initiation (28-36 hpf) and gradually increased from $52 \mathrm{hpf}$ to $4 \mathrm{dpf}$ (Fig. S6), suggesting a role for sart3 in HSPC expansion and maintenance within the $\mathrm{CHT}$ region.

We thereby examined cell proliferation and cell death in sart $3^{\text {smu471 }}$ mutant HSPCs in the $\mathrm{CHT}$ region. We monitored $\mathrm{CHT}$ region HSPC status using 2.5 -dpf inter-crossed progenies of the sart ${ }^{+/ s m u 471} ; \mathrm{Tg}(\mathrm{cd} 41: \mathrm{eGFP})^{+/+}$transgenic zebrafish. Measurement of cell proliferation by the bromodeoxyuridine (BrdU) incorporation assay found the percentage of BrdU labeled cd41:eGFPlow HSPCs (eGFPlow; BrdU double positive cells) to be significantly reduced in sart $3^{\text {smu471 }}$ mutants compared to their sibling controls (Fig. 3A, B), suggesting that HSPC proliferation was attenuated by the sart3 mutation. We then monitored cell death in the sart $3^{\text {smu471 }}$ mutant by terminal deoxynucleotidyl transferase (TdT)-mediated dUTP nick-end labeling (TUNEL) assay. Results showed the percentage of cd41:eGFPlow and TUNEL double positive cells to be significantly increased (Fig. 3C, D), suggesting that HSPC maintenance was also affected by the sart3 mutation. Taken together, the above data suggest that the HSPC deficiency in sart $3^{\text {smu471 }}$ mutant is due to both decreased cell proliferation and increased cell death.

The HSPC defect in the sart $3^{\text {smu471 }}$ mutant is p53 dependent Previous analysis has shown SART3 to control CMYC and GATA2 expression during mouse BM hematopoiesis [36], which could partially explain adult HPC cell cycle defects caused by a Sart3 deficiency. Yet, how Sart3 regulates embryonic HSPC proliferation 

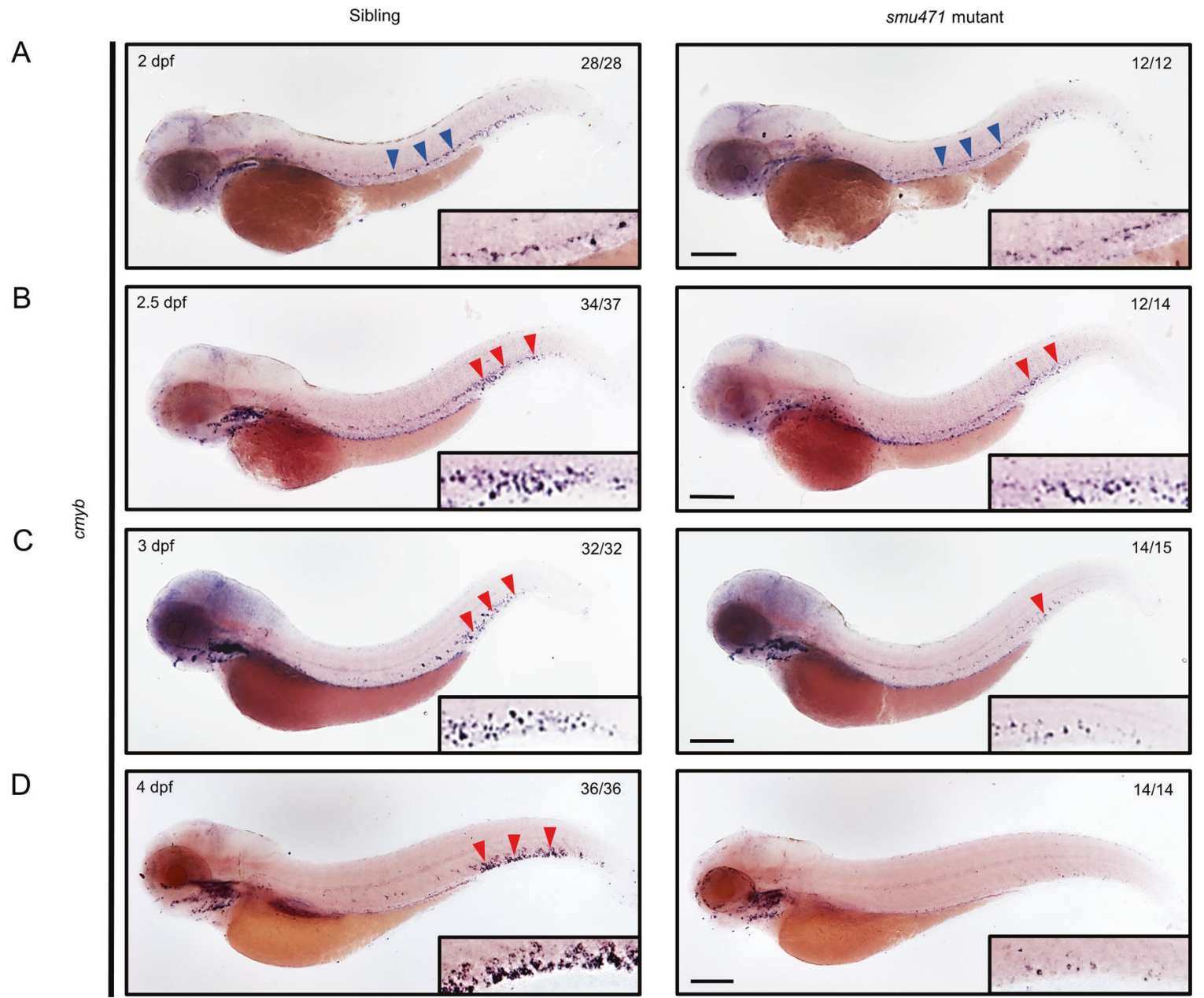

Fig. 1 Decreased HSPCs in the CHT region of zebrafish smu471 mutants. A-D cmyb WISH identified HSPCs from 2 to 4 dpf in smu471 mutants (right) compared with their siblings (left). A $c m y b^{+}$signals were not altered at $2 \mathrm{dpf}$ in the VDA region (blue arrowheads indicate signals in the region). B In the $\mathrm{CHT}$ region, $\mathrm{Cmyb}^{+}$signals were decreased slightly at $2.5 \mathrm{dpf}$ in smu471 mutants (red arrowheads indicate signals in the region). C, D Severely decreased $c m y b^{+}$signals in the $\mathrm{CHT}$ region at $3 \mathrm{dpf}(\mathbf{C})$ with a further reduction at $4 \mathrm{dpf}(\mathbf{D})$ in smu471 mutants. The boxed regions in the lower right corner are magnifications. Scale bars: $200 \mu \mathrm{m}$.

and maintenance is still unclear. To analyze the molecular mechanism, we performed RNA sequencing (RNA-seq) analysis to assess Sart3 regulation of HSPC expansion. Since the HSPC defect was evident at $4 \mathrm{dpf}$, RNA from sart $3^{\text {smu471 }}$ mutants and their wild-type siblings at this stage was collected for sequencing. Distance heatmap analysis of siblings and sart3 $3^{\text {smu471 }}$ mutants showed correlations for each biological replicate. Siblings and sart $3^{\text {smu471 }}$ mutants could be divided into two clusters (Fig. 4A). Through Kyoto Encyclopedia of Genes and Genomes (KEGG) pathway analysis, we found that the 'spliceosome' and the 'p53 signaling pathway' were the most significantly enriched pathways in sart $3^{\text {smu471 }}$ mutants compared with their siblings (Fig. 4B). Specifically, we found a series of genes (ccng1, p21, gadd45, baxa, casp8, $p 53$, and $m d m 2$ ) that were upregulated by sart3 mutation (Fig. 4C), all of which were related to p53 involved cell cycle or apoptosis pathways. To validate the RNA-seq data, we evaluated gene expression by real-time quantitative polymerase chain reaction (RT-qPCR). Consistent with the RNA-seq data, expression of $p 53$-related genes was significantly elevated in sart3 ${ }^{\text {smu471 }}$ mutants compared with siblings (Fig. 4D), confirming activation of the p53 pathway in the sart3 $3^{\text {smu471 }}$ mutants. To determine whether p53 pathway activation occurred in mutant HSPCs, we examined $p 53$-related upregulated gene expression in sorted cd41:eGFPlow labeled HSPCs. We found the expression of these genes to be significantly upregulated in the HSPCs of sart3 ${ }^{\text {smu471 }}$ mutants compared with their siblings (Fig. 4E), indicating the HSPC defect to be associated with p53 pathway activation.

We also found the level of p53 protein to be increased in sart3 $3^{\text {smu471 }}$ mutants compared with their siblings (Fig. 4F), confirming the p53 activation by sart3 mutation. It is reported that p53 pathway activation is associated with cell cycle arrest and apoptosis [48]. Furthermore, our results suggest that sart3 may regulate HSPC proliferation and apoptosis through activation of the p53 pathway. To assess this possibility, we outcrossed a sart3 heterozygote with a $p 53^{M 214 K}$ mutant in which $p 53$ function was reported to be abrogated [49]. Unfortunately, we failed to obtain a double mutant because of the short distance between sart 3 and p53 genes on chromosome 5 . As an alternative, we knocked down p53 in sart3 $3^{\text {smu471 }}$ mutants by $p 53$ morpholino oligonucleotide (MO). As expected, downregulation of p53 rescued the HSPC (Fig. 4G) and lymphoid defect (Fig. 4H) in sart $3^{\text {smu471 }}$ mutants. Collectively, these results demonstrate that sart3 regulates HSPC development through the p53 pathway.

\section{sart3 mutation induces AS of $\mathbf{m d m} 4$}

Previous studies have demonstrated SART3 to promote assembly of U4/U6 snRNPs $[32,50]$. Deletion of SART3 reduces functional U4/U6 di-snRNPs which have an essential role in pre-mRNA splicing [32]. To assess sart3 regulation of HSPC development, we 
A

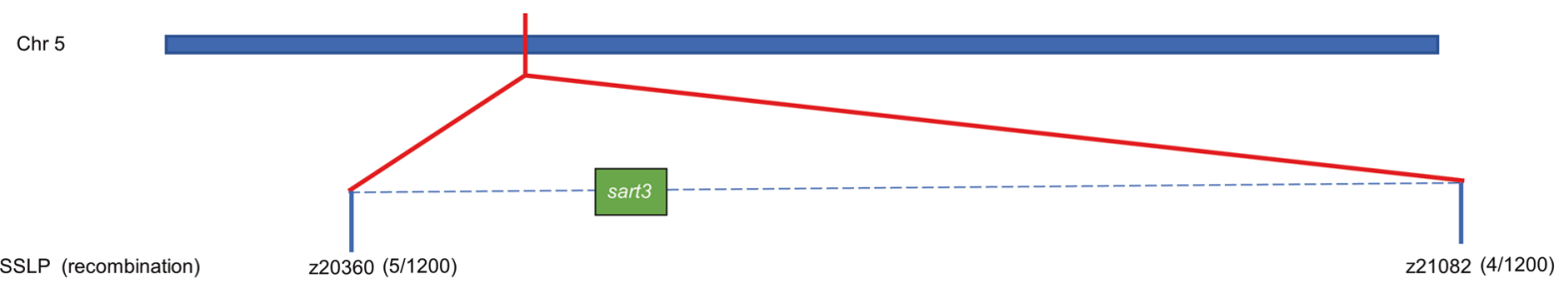

B

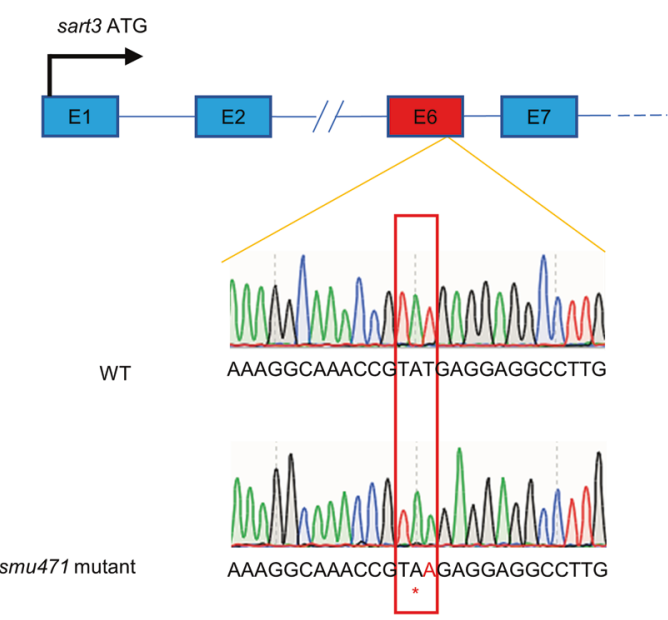

C

WT

smu471 mutant

$\mathrm{E}$

WT

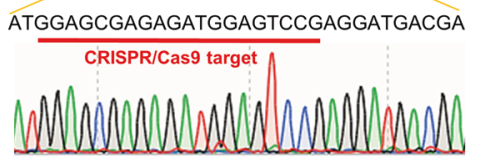

$\operatorname{sart3}^{(\Delta 14,+4)}$ mutant

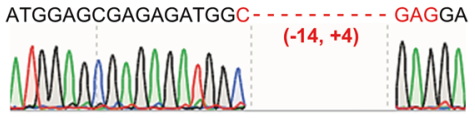

F

WT

RRM domain

sart3 ${ }^{(414,+4)}$ mutant
RRM domain

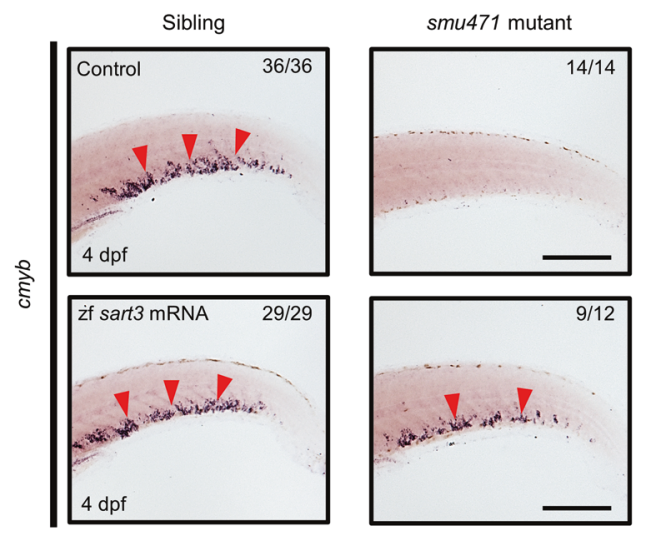

G

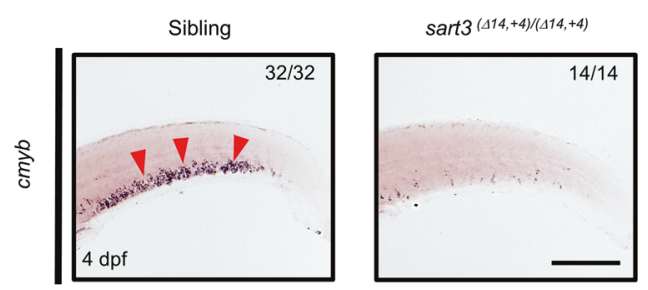

$\mathrm{H}$

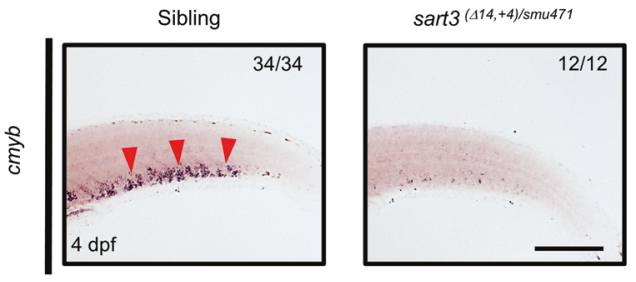

Fig. 2 sart3 is the causative gene of the zebrafish smu471 mutation. A Genetic map of the candidate region on chromosome 5 (Chr 5 )

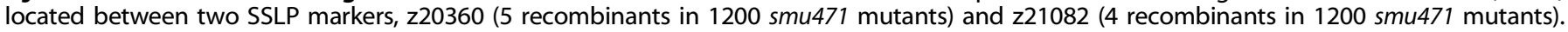

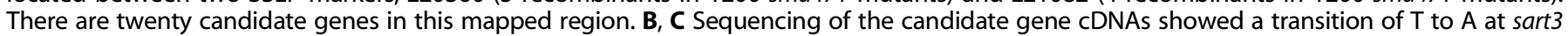

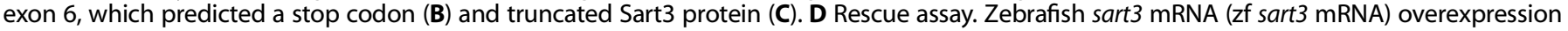

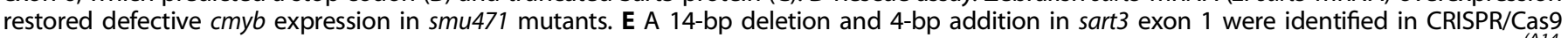

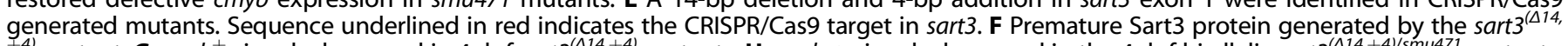

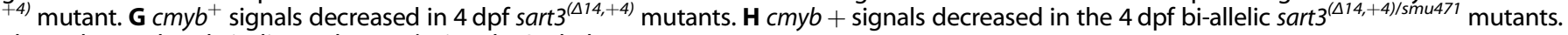
The red arrowheads indicate the $c m y b$ signals. Scale bars: $200 \mu \mathrm{m}$. 


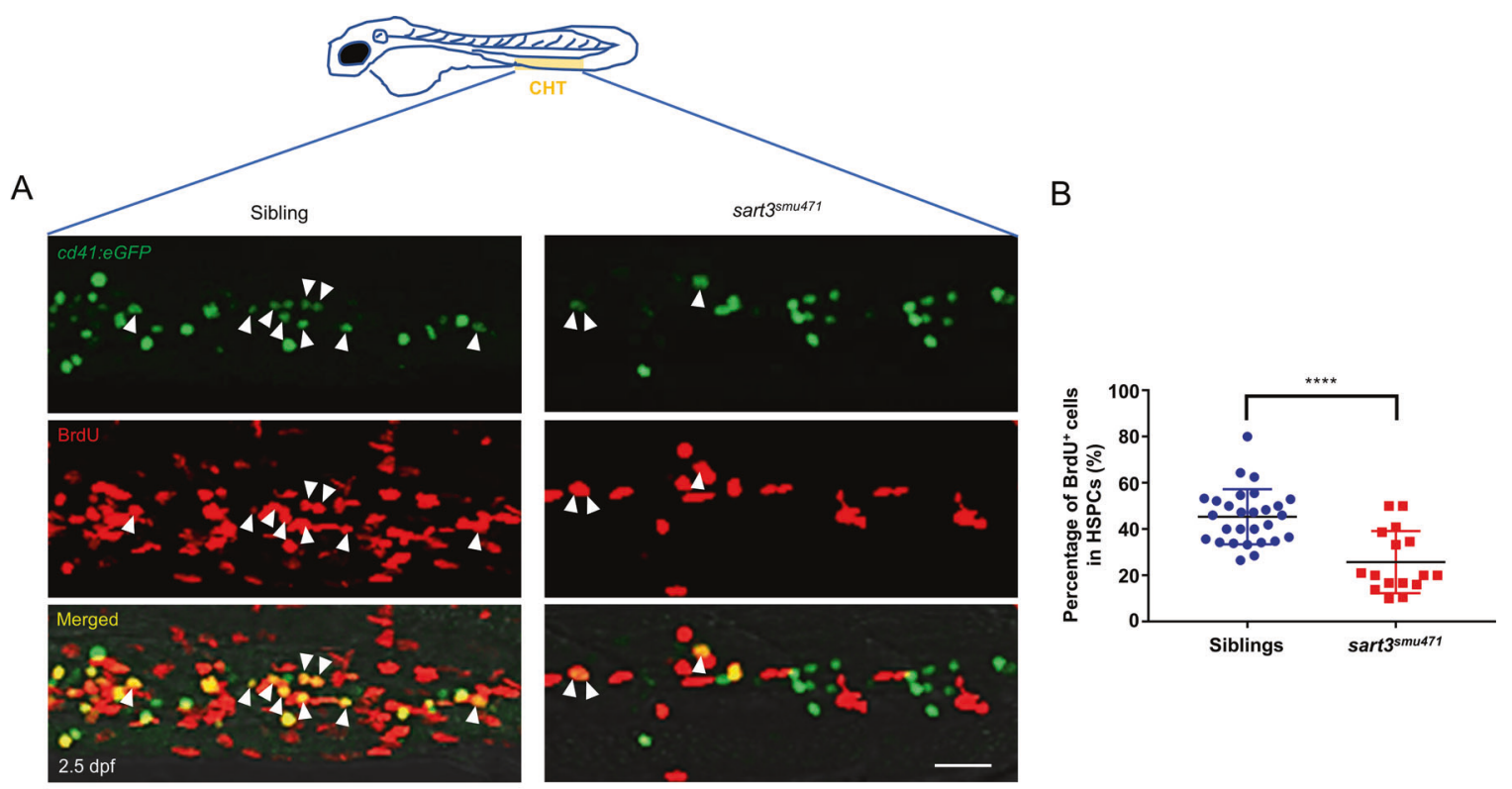

C
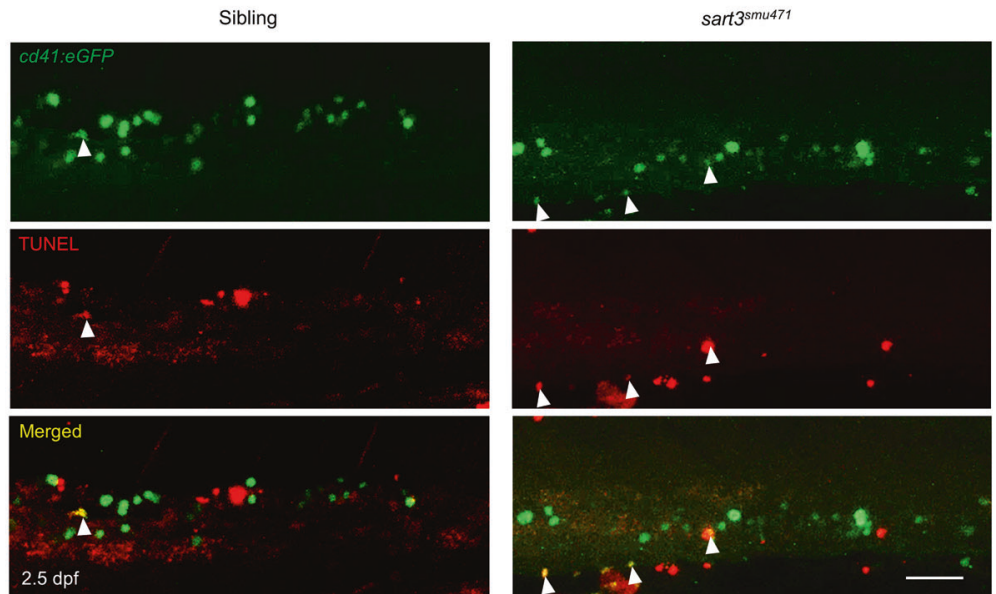

D

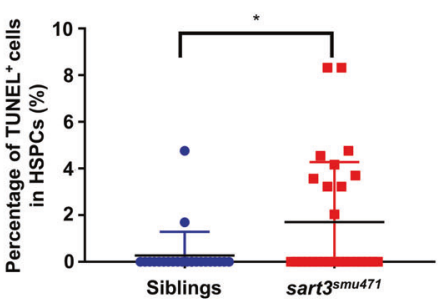

Fig. 3 Decreased HSPC proliferation and increased apoptosis in sart3 $3^{\text {smu471 }}$ mutants. A, B Decreased HSPC proliferation in $5 a r t 3^{\text {smu471 }}$ mutants. A The BrdU incorporation assay. The white arrowheads indicate proliferating HSPCs (cd41:eGFPlow; BrdU double positive cells). Green indicates eGFP, red indicates BrdU. B Statistical analysis of the percentage of CHT localized cd41 ${ }^{\text {low }}$ HSPCs that incorporate BrdU (Student's $t$-test, means \pm SD; siblings, $n=28$; sart $3^{\text {smu471 }}$ mutants, $\left.n=16 ;{ }^{* * * *} P<0.0001\right)$. C, D Increased HSPC death in sart $3^{\text {smu471 }}$ mutants. C The TUNEL assay. The white arrowheads indicate HSPCs undergoing cell death ( $c d 41: e G F P^{\text {low; }}$ TUNEL double positive cells). Green indicates eGFP, red indicates TUNEL. D Statistical analysis of the percentage of CHT localized $c d 41^{\text {low }}$ HSPCs labeled by TUNEL (Mann-Whitney U test, means \pm SD; siblings, $n=24$; sart $3^{\text {smu471 }}$ mutants, $\left.n=27 ;{ }^{*} P<0.05\right)$. Scale bars: $50 \mu \mathrm{m}$.

completed AS analysis based on RNA-seq data. We identified 2075 sart3-affected AS events including; 1327 skipped exons, 159 retained introns, 145 alternative $3^{\prime}$ splice sites, 81 alternative $5^{\prime}$ splice sites, and 363 mutually exclusive exons (Fig. S7A). To determine whether sart3-affected AS events associated with p53 activation, we analyzed genes differentially expressed in the sart $3^{\text {smu471 }}$ mutant (5424 genes) with AS (2002 genes) and found 607 genes that overlapped (Fig. 5A). Based on the overlapped genes, we performed Gene Ontology (GO) term enrichment analysis and KEGG pathway analysis using the Metascape database [51] and found 'mRNA processing' to be the most enriched pathway (Fig. 5B). The 'p53 signaling pathway' was also enriched (Fig. 5B). Clustering analysis of the enriched p53 signaling pathway showed that seven genes (ptenb, adgrg6, thbs 1b, adgrb1a, ccnd2a, p53, and baxa) were upregulated and six genes (ddb2, tek, elmo1, mdm4, rrm2, and syk) were downregulated (Fig. 5C). Of note, based on replicate multivariate analysis of transcript splicing (rMATS) analysis, $m d m 4$ in sart3 $3^{\text {smu471 }}$ mutants lacked exon 6 (Fig. S7B), which would result in a truncated $m d m 4$ transcript (mdm4-S) [52]. After analysis of the $m d m 4$ transcript ratio between the $m d m 4$ full-length transcript ( $m d m 4-F L$ ) and $m d m 4-S$, we found that $m d m 4-F L$ was decreased in sart $3^{\text {smu471 }}$ mutants compared with siblings, whereas the $m d m 4-S$ was increased (Fig. 5D). By monitoring expression of $m d m 4-F L$ in sart3 mutants, we found levels to be decreased at 2.5 and $4 \mathrm{dpf}$ (Fig. 5E), which suggested an insufficiency of the correct mdm4 transcripts during zebrafish development.

MDM4 was known to inhibit the transcription of p53 by binding its transactivation domain [53], and promote p53 protein degradation by interacting with MDM2 [54]. Besides, p53 could regulate itself transcription [55]. Thus, we speculated that elevated p53 expression and enhanced protein activity in sart $3^{\text {smu471 }}$ mutants were attributed to AS and downregulation of $m d m 4$. To confirm the role of $m d m 4$ in sart3-regulation of HSPC 
development, we performed a functional assay that restored mdm4 in sart $3^{\text {smu471 }}$ mutants. We found that decreased HSPCs in sart $3^{\text {smu471 }}$ mutants could be partially rescued by overexpressing mdm4 (Fig. 5F, G), suggesting that HSPC deficiency due to sart3 mutation was, at least in part, a result of $m d m 4$ insufficiency.

\section{DISCUSSION}

In this study, we mapped the zebrafish smu471 mutation and identified a sart3 nonsense mutant that disrupted early HSPC development resulting in definitive hematopoiesis failure. Furthermore, we showed that splicing dysregulation and p53 pathway
A

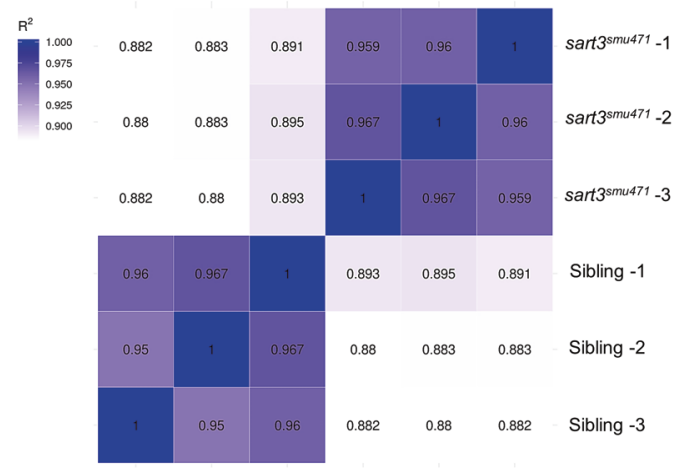

C

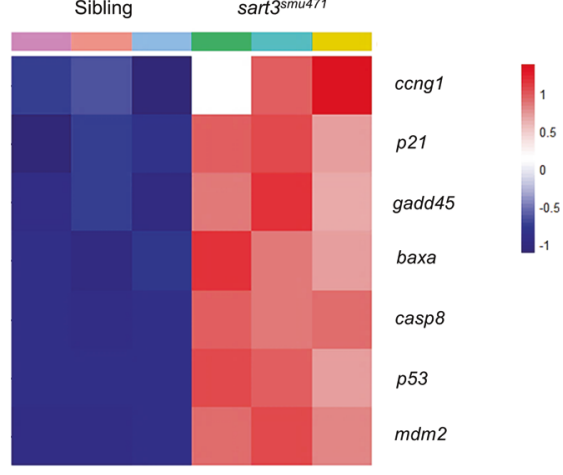

$E$

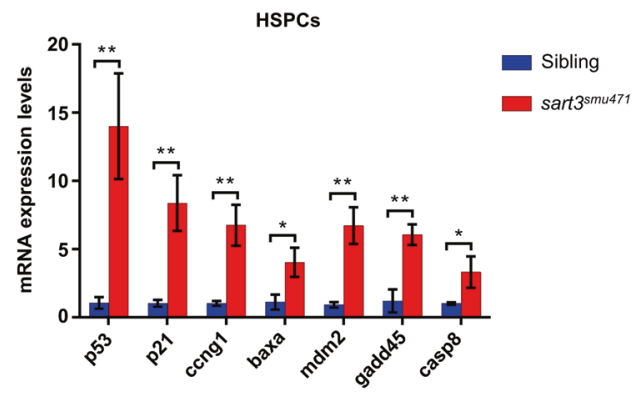

G

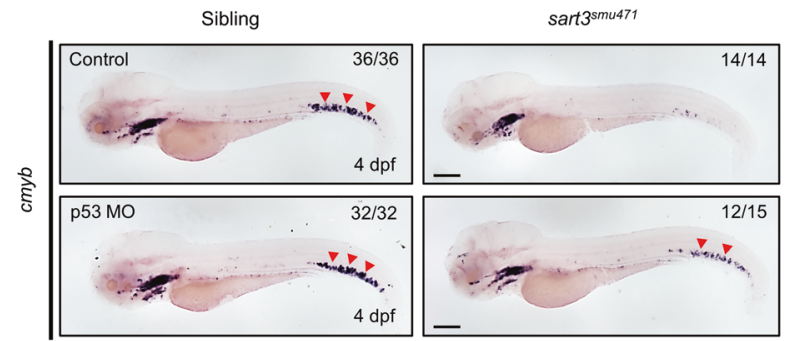

B

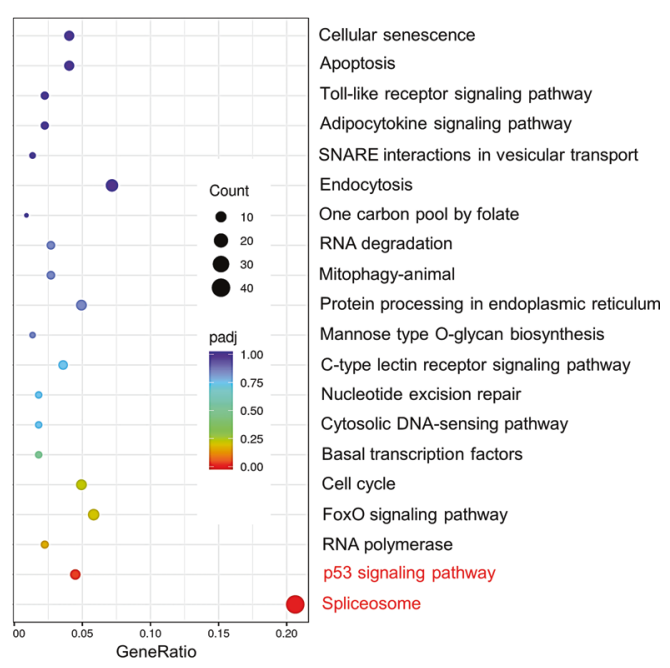

D

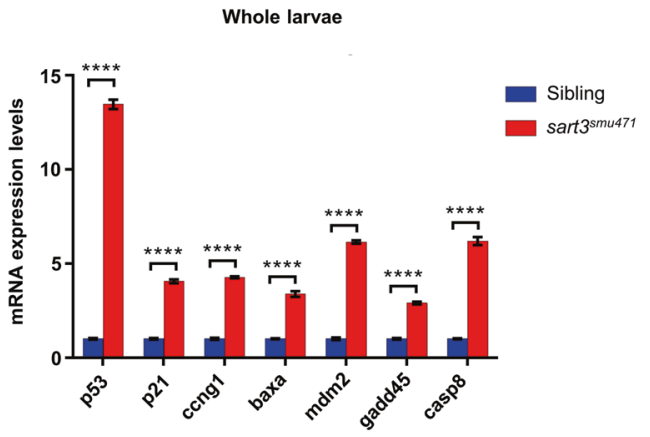

F

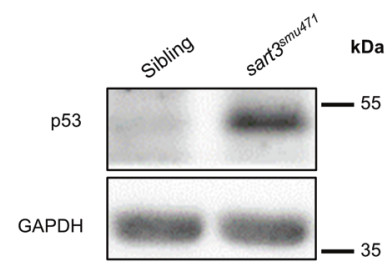

$\mathrm{H}$

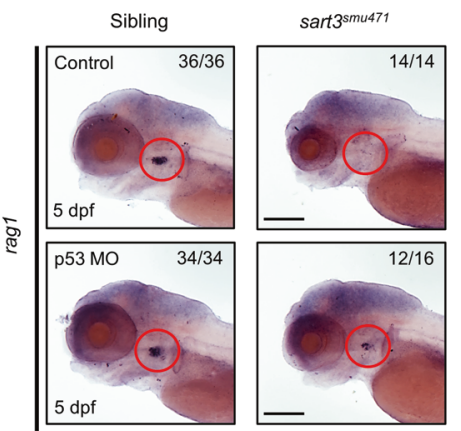


Fig. 4 Reductions in HSPCs are p53 dependent in sart $3^{\text {smu471 }}$ mutants. A Distance heatmap analysis of WT siblings and sart ${ }^{\text {smu471 }}$ mutants. The color scale is shown on the left. The deeper the blue block the less different the samples are. B Spliceosome and p53 signaling pathway enrichment in sart $3^{\text {smu471 }}$ mutants by KEGG analysis of the RNA-seq data. C Heatmap demonstrating upregulation of p53 pathway genes in sart3 $^{\text {smu471 }}$ mutants (data was normalized by Z-score, Z-score was shown on the right). D, E RT-qPCR validation of the RNA-seq data. Upregulation of $p 53$ and its downstream target genes $p 21$, ccng1, baxa, mdm2, gadd45, and casp8 in sart3 ${ }^{\text {smu471 }}$ whole larvae (D) and HSPCs (E) at $4 \mathrm{dpf}$ (Student's $t$-test, means $\pm \mathrm{SD}, n \geq 15$ per group for whole larvae, $n \geq 2 \times 10^{4}$ per group for HSPCs, ns: not significant, ${ }^{*} P<0.05$, ${ }^{* *} P<$ $\left.0.01,{ }^{* * * * P}<0.0001\right)$. F Increased p53 protein in 4 dpf sart $3^{\text {smu } 471}$ mutants by western blot analysis. GAPDH was used as the loading control. G, H Phenotype restoration in p53 knockdown sart $3^{\text {smu } 471}$ mutants. Red arrowheads indicate WISH signals of $\mathrm{cmyb}$ at $4 \mathrm{dpf}$ in the $\mathrm{CHT}$ region (G) and red circles indicate rag1 signals at $5 \mathrm{dpf}$ in the thymus region (H). Scale bars: $200 \mu \mathrm{m}$.

activation resulted in definitive hematopoiesis failure in sart3 $3^{\text {smu471 }}$ mutants. Overall, these results demonstrate that impairment of mdm4 by sart 3 mutation activates $\mathrm{p} 53$ and its downstream pathway, affecting HSPC proliferation and apoptosis during early hematopoiesis (Fig. 6).

During adult hematopoiesis, mouse Sart3 has been associated with HPC numbers, survival, and cell cycling, which are likely linked to regulation of CMYC [36]. In early hematopoiesis, study of the zebrafish egy mutation (another sart3 zebrafish mutant) found that sart3 mutation resulted in multi-organ defects including a definitive hematopoiesis defect in which the T cell marker (rag1) was absent but primitive erythropoiesis intact [43]. Whether and how developing HSPCs of the egy mutant are affected remain unknown. In the present study, we report the smu471 zebrafish to be a different allele of the sart3 mutant. The smu471 mutation exhibited microcephaly and microphthalmia at $4 \mathrm{dpf}$ with death at $\sim 8 \mathrm{dpf}$ (data are not shown). Notably, the smu471 mutant had definitive hematopoiesis failure identical to the egy mutant. Primitive hematopoiesis and definitive HSPC initiation were not disrupted. We attributed definitive hematopoiesis failure to decreased proliferation and increased apoptosis of HSPCs by the smu471 mutation. Taken together, our results and those of others identify a critical role for sart3 in various HSPC development and maintenance stages.

We found the 'spliceosome' and the 'p53 signaling pathway' to be the most enriched pathways in the sart $3^{\text {smu471 }}$ mutant by KEGG pathway enrichment analysis of the RNA-seq data. Consistent with our findings, previous microarray analysis of the egy mutant showed that half of upregulated genes were snRNP encoding genes and splicing-related factors [43]. Similarly, we also noticed p53 upregulated in egy mutant. These observations suggest that both egy and smu471 sart3 mutation alleles affect hematopoietic development by control of similar molecular pathways.

It is well-known that p53 plays essential roles in cell cycle control and cell death [56,57]. Further, p53 is highly expressed in HSPCs, wherein it mediates quiescence, self-renewal, and apoptosis [58, 59]. Knock down of SART3 in hypoxic human U2OS cancer cells significantly decreased p53 protein levels, and p53 could activate SART3 transcription [37]. However, in whole zebrafish larvae and in endogenous HSPCs, p53 and its regulated genes were elevated by sart 3 mutation. In addition, downregulation of p53 efficiently restored HSPC numbers in zebrafish. Reduced HSPC levels were due to decreased cell proliferation and increased apoptosis in the sart $3^{\text {smu471 }}$ mutant. Our speculation is that sart3 maintenance of HSPC development is due to p53-dependent inhibition of cellular proliferation and enhanced apoptosis.

Sart3 is known to be a recycling factor for spliceosome assembly [43]. The 'spliceosome' is also the most enriched pathway in the sart $3^{\text {smu471 }}$ mutant RNA profile. The sart $3^{\text {smu471 }}$ mutant exhibited a transcriptome-wide RNA splicing defect. Several reports suggest that p53 activation may be a consequence of a spliceosome defect [60-62], with our results providing new evidence supporting this hypothesis. It is known that MDM4 could inhibit the transcription of p53 and stimulate the MDM2-mediated protein degradation of p53 $[53,54]$. We found $m d m 4$ to undergo significantly reduced expression along with disrupted AS. Mdm4 expression was changed by sart3 mutation, which is consistent with a report demonstrating reduced $m d m 4$ expression to interfere with the spliceosome [60]. Zebrafish AS of $m d m 4$ in which exon 6 is skipped in the sart $3^{\text {smu47i }}$ mutant is similar to another HSPC deficient zebrafish spliceosome mutant, bcas $2^{-1-}[62]$ and to the skipping of exon 6 in human or exon 7 in mouse $[63,64]$. A truncated transcript termed mdm4-S was previously identified [52]. The conservation of spliceosomeaffected mdm4 and p53 activation across species suggests a general spliceosome-mdm4-p53 regulatory pathway in vertebrates.

Moreover, SART3 alteration may be a favorable index for cancer diagnosis, prognosis, and therapy. For example, SART3 expression may be a diagnostic and prognostic indicator of melanoma [65]. Antisense oligonucleotides-mediated MDM4 exon 6 skipping could prove useful as a therapeutic strategy for breast carcinoma, melanoma, and diffuse large B cell lymphoma (DLBCL), by decreasing MDM4 abundance and reducing the growth of these tumors [63]. Interestingly, we found several DLBCL cases with SART3 alteration in the cBioPortal database (data are not shown). Thus, whether SART3 is a candidate prognostic marker or a therapeutic target for $D L B C L$ is worth future investigation. We have shown that human SART3 mRNA rescues the zebrafish sart $3^{\text {smu471 }}$ mutant (Fig. S5B). The sart $3^{\text {smu471 }}$ zebrafish could serve as an in vivo model for functional validation of patientderived mutations as well as a tool for cancer therapeutic approach development.

Taken together, this study describes a novel function for sart3 in which HSPC proliferation and apoptosis are regulated. Further, we found that AS disruption in the sart $3^{\text {smu471 }}$ mutant included effects on the p53 repressor, mdm4, which activated p53. Activated p53 was triggered by $m d m 4$ exon 6 skipping and therefore sart3 mutation may be a favorable prognostic marker or a potential therapeutic target for some cancers. This study expands understanding of the mechanisms that regulate HSPC development and sheds light on the mechanistic basis and potential therapeutic treatments for sart3 related disorders.

\section{MATERIALS AND METHODS}

\section{Zebrafish strains}

Zebrafish were raised and maintained in standard conditions [66] with a 14-h light/10-h dark cycle at $28.5^{\circ} \mathrm{C}$. The following zebrafish strains were used; AB, WIK, $\operatorname{Tg}(c d 41: e G F P)$ [67], sart $3^{\text {smu471 }}$, and $p 53^{M 214 K}$ [49].

\section{Genetic mapping and positional cloning}

Mapping family generation and positional cloning were performed as previously described [68]. Heterozygous smu471 [45] were outcrossed to the mapping strain WIK to generate the F1 mapping population, which would be further intercrossed to generate F2 gynogenetic diploid offspring. To verify the mutant phenotype, F2 individuals were subjected to whole mount in situ hybridization (WISH) by rag1 antisense probe at $5 \mathrm{dpf}$ for genetic mapping. The candidate interval was flanked by two SSLP markers: z20360 and $z 21082$. The 20 candidate genes in this region were all subjected to exon region sequencing in both siblings and smu471 mutants.

\section{Generation of sart3 mutants by CRISPR/Cas9}

sart3 $3^{(\Delta 14,+4)}$ mutants were generated using the CRISPR/Cas9 system [69]. The guide RNA (gRNA) targeting sequence was as follows: 5'-GGAGCGA GAGATGGAGTCCG-3', with the gRNA synthesized using T7 RNA polymerase (EP0111, Thermo Fisher Scientific, San Jose, CA, USA). 
The mixture of gRNA target $(500 \mathrm{ng} / \mu \mathrm{L})$ and Cas 9 protein $(600 \mathrm{ng} / \mu \mathrm{L})$ (M0646M, New England Biolabs, Ipswich, MA, USA) was co-injected into one-cell stage embryos and the mutation efficiency assessed by T7E1 (M0302S, New England Biolabs) digestion. The injected embryos were raised to sexual maturity and screened for a stable F2 heterozygous phenotype of interest.
A

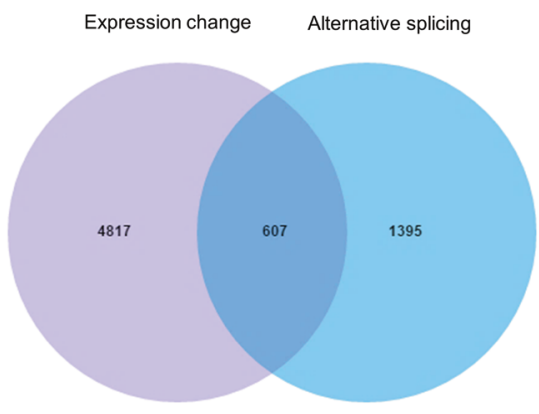

C

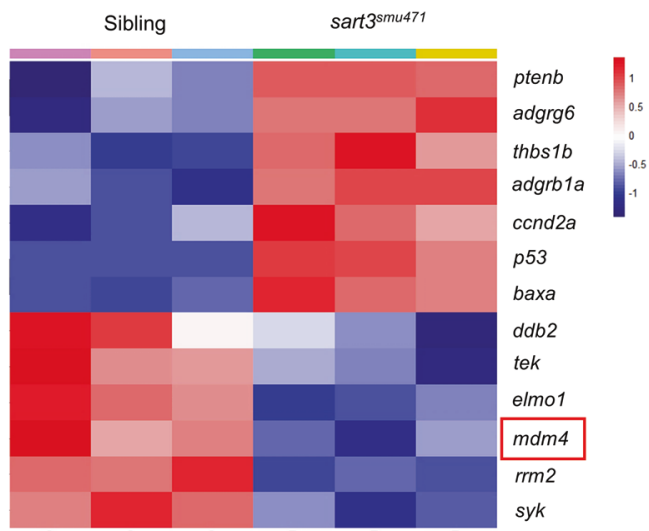

Microinjection of mRNAs, plasmids, and MO

The coding sequence of sart3 was PCR amplified and cloned into the $\mathrm{pCS}^{+}$ vector, then the sart3 mRNA was synthesized in vitro by MMESSAGE mMACHINE ${ }^{T M}$ SP6 in vitro Transcription Kit (AM1340, Invitrogen, Carlsbad, (A, USA). The coding sequence of $m d m 4$ was PCR amplified and cloned into the pTol2-hsp 70 vector. The p53 MO (5'-GCGCCATTGCTTTGCAAGAATTG-3')
B

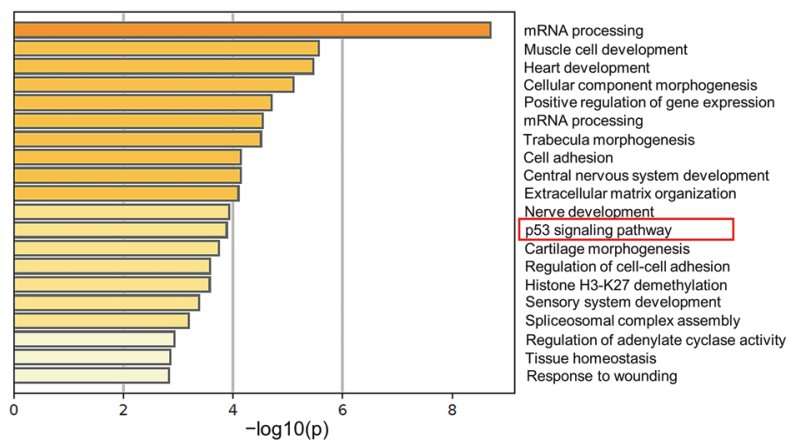

D

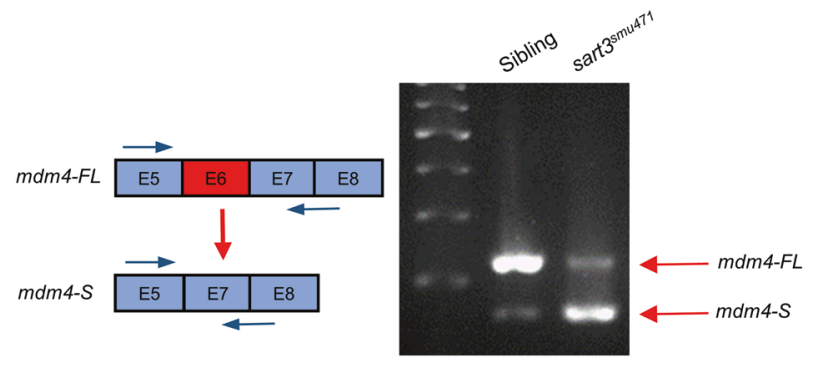

E

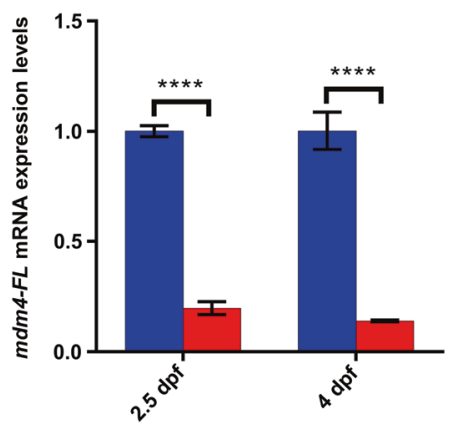

Sibling

sart3smu471

$\mathrm{F}$

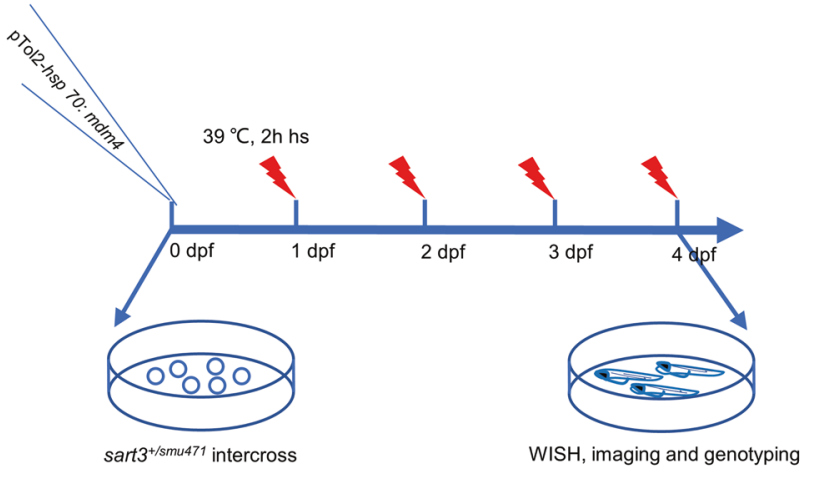

G

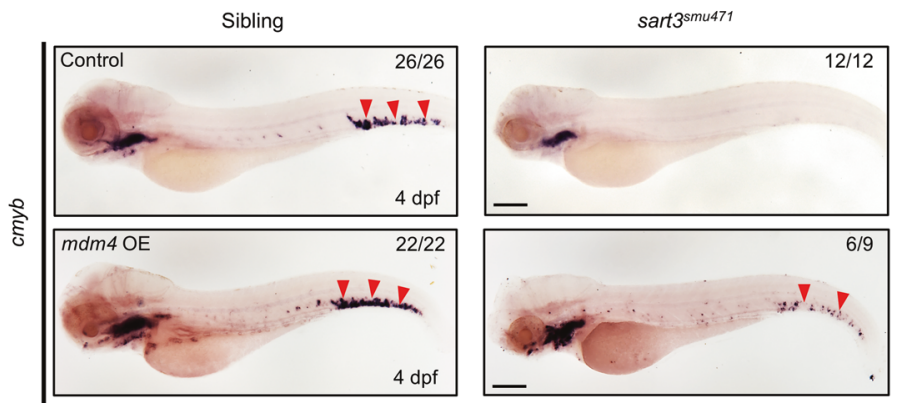


Fig. 5 The sart 3 mutation triggers alternative splicing of $\mathbf{m d m} \mathbf{4}$ as well as the activation of the p53 pathway. A Overlap of gene expression change (padj < 0.05) with alternative splicing (padj <0.05) in sart3 $3^{\text {smu471 }}$ mutants from RNA-seq data. The overlapping number is 607 . B p53 signaling pathway enrichment by GO term enrichment and KEGG pathway analyses from the 607 overlapped genes. The horizontal axis represents the significance, $-\log 10(\mathrm{p})$. C Heatmap of p53 signaling pathway-related gene changes exhibited in (B) (data was normalized by Z-score, Z-score was shown on the right). The p53 negative regulator, $m d m 4$, is boxed. D $m d m 4$ alternative splicing and primers designed for PCR detection of exon 6 skipping. The $m d m 4$ full-length transcript ( $m d m 4-F L$ ) decreases and truncated $m d m 4$ transcript ( $m d m 4-S$ ) increase in sart $3^{\text {smu471 }}$ mutants. E Decreased expression of $m d m 4-F L$ by RT-qPCR at $2.5-4 \mathrm{dpf}$ sart $3^{\text {smu471 }}$ mutants (Student's $t$-test, means \pm SD, $n \geq 15$ per group, $\left.{ }^{* * *} P<0.0001\right)$. F The procedure for the $m d m 4$ overexpression rescue of reduced HSPCs in sart $3^{\text {smu471 }}$ mutants. hs: heat shock. G Partial restoration of $c m y b$ signals in sart $3^{\text {smu471 }}$ mutants by $m d m 4$ overexpression (OE). Red arrowheads indicate $c m y b$ signals by WISH in the CHT region of $4 \mathrm{dpf}$ larvae. Scale bars: $200 \mu \mathrm{m}$.
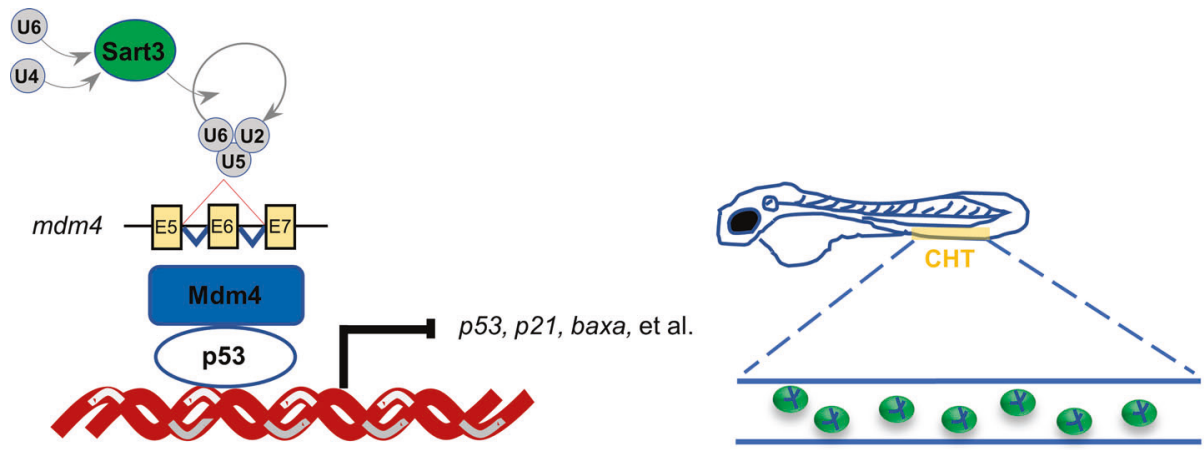

HSPC development
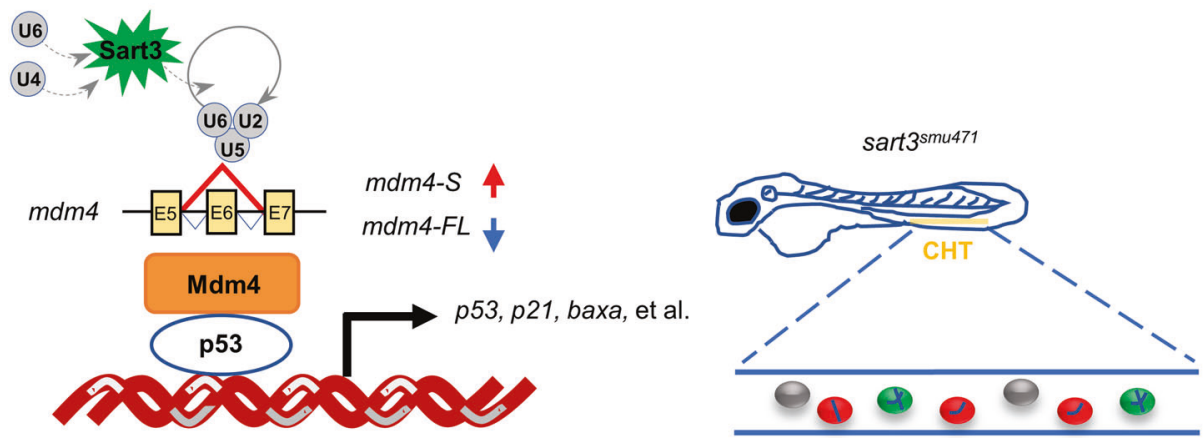

HSPC expansion arrest HSPC apoptosis

Fig. 6 Schematic diagram of Sart3-Mdm4-p53-regulated HSPC development in zebrafish. Schematic diagram of HSPC development regulated by Sart3-Mdm4-p53 pathway in zebrafish. Sart3, which could recycle U4 and U6 snRNPs into spliceosome assembly to affect premRNA splicing [43], promotes HSPC development (current study). Mutation of Sart3 (highlighted in burst) reduces efficient recycling of U4 and U6 snRNPs (broken lines) so that normal splicing of $m d m 4$ is disrupted. Mdm4 exon 6 (E6) skipping by sart3 mutation results in increased truncated $m d m 4$ transcript ( $m d m 4-S$ ) and decreased $m d m 4$ full-length transcript (mdm4-FL). The insufficiency of Mdm4 (orange rectangle) triggers activation of p53 pathway and promotes HSPCs to undergo proliferation arrest and apoptosis in zebrafish early hematopoiesis.

was ordered from Gene Tools as described previously [70]. Microinjection was conducted with $1.5 \mu \mathrm{g} / \mu \mathrm{L}$ sart3 mRNA, $70 \mathrm{ng} / \mu \mathrm{L}$ pTol2-hsp 70: $\mathrm{mdm} 4$, and $1 \mathrm{mM} \mathrm{p} 53 \mathrm{MO}$. The construction primers of sart 3 and $m d m 4$ used in this study are listed in Table S1.

\section{WISH and genotyping}

WISH was performed as described previously [71]. After imaging, the DNA of whole embryo/larva was extracted for genotyping to distinguish sart ${ }^{3 m u 471}$ mutants and siblings. PCR was performed to obtain DNA fragments including the point mutation site (forward primer: $5^{\prime}$-GACTGGGCAGATGATGGCGT-3'; reverse primer: $5^{\prime}$-CACCGCATCTGCTCCCAGAGAC-3'), then the PCR products were analyzed by high-resolution melting (HRM) genotyping, with the wild type (WT) and mutant showing one peak and the heterozygote showing two different peaks to initially distinguish those that were heterozygous. Next, we added pre-prepared WT PCR products to the one peak samples for second round HRM analysis, such that the WT showed one peak while the mutant showed two different peaks, as heterozygous.

\section{Antibody staining}

Progenies of the intercrossed $s a r t 3^{+/ s m u 471} ; \operatorname{Tg}\left(\text { cd }_{41} \text { :eGFP }\right)^{+/+}$transgenic zebrafish were fixed and antibody staining was performed as previously described [72]. Primary antibody anti-GFP (1:400, ab6658, Abcam, Cambridge, UK) and secondary antibody Alexa Fluor 488-conjugated anti-goat (1:400, A32814, Invitrogen) were used. Images were captured using a Zeiss LSM800 laser scanning confocal microscope and cd41:eGFPlow labeled HSPCs were distinguished from cd41:eGFPhigh labeled thrombocytes [46] by the Range Indicator tool of ZEN software according to fluorescence intensities.

\section{BrdU incorporation and double staining}

Progenies of the intercrossed $5 a r t 3^{+/ s m u 471} ;{\operatorname{Tg}(c d 41: e G F P)^{+/+}}$transgenic zebrafish were treated with $10 \mathrm{mM} \mathrm{BrdU}$ for $3 \mathrm{~h}$ at $28.5^{\circ} \mathrm{C}$. After fixation, dehydration, rehydration, and digestion with proteinase $\mathrm{K}, \mathrm{BrdU}$ labeled embryos were incubated with anti-BrdU (1:50, 111703760001, Roche, Basel, Switzerland) and anti-GFP (1:400, ab6658, Abcam), then incubated with goat Alexa Fluor 555-conjugated anti-mouse (1:400, A31570, Invitrogen) and donkey Alexa Fluor 488-conjugated anti-goat (1:400, A32814, Invitrogen) secondary antibodies for immunofluorescent staining as previously described $[73,74]$. The fluorescent images were captured using a Zeiss LSM800 laser scanning confocal microscope with a dual laser channel. According to fluorescence intensities, cd41:eGFPlow labeled HSPCs were distinguished from $c d 41$ :eGFPhigh labeled thrombocytes as mentioned 
above. Double-positive cells were identified by layer-to-layer examination. Statistical analysis was performed after distinguishing siblings and mutants by HRM genotyping of each sample.

\section{TUNEL immunostaining and double staining}

TUNEL was performed with an In Situ Cell Death Detection Kit TMR red $\left(12156792910\right.$, Roche) as described [73, 74]. Initially, the sart $3^{+/ s m u 471} ; \mathrm{Tg}$ $(c d 41: e G F P)^{+/+}$transgenic zebrafish intercrossed progenies were fixed, dehydrated, rehydrated, and digested with proteinase $\mathrm{K}$. After incubation with permeabilization solution (acetone:ethanol $=1: 2$ ) at $-20^{\circ} \mathrm{C}$ for $7 \mathrm{~min}$, the embryos were rinsed and stained with the Kit according to the manufacturer's instructions. Imaging, quantification, and statistical analysis were carried out as described above.

\section{RNA-seq and RT-qPCR}

Total RNA of desired stage embryos/larvae or sorted-HSPCs was extracted using Trizol reagent (15596026, Invitrogen) according to the manufacturer's instructions. For RNA-seq, the sequencing libraries were generated by NEBNext ${ }^{\circledR}$ UltraTM RNA Library Prep Kit for Illumina ${ }^{\circledR}$ (E7770, New England Biolabs). For RT-qPCR, CDNA was prepared with HiScript Q RT SuperMix for qPCR (+gDNA wiper) (R323-01, Vazyme, Nanjing, China). The RT-qPCR was performed using PowerU ${ }^{\text {TM }}$ SYBR $^{\circ}$ Green Master Mix (4472908, Thermo Fisher Scientific) in a LightCycler 96 system (Roche). The RT-qPCR primers used in this study are listed in Table S2.

\section{AS analysis and detection}

For AS events analysis, rMATS software was used [75]. For mdm4 AS detection, CDNA of sart $3^{\text {smu471 }}$ mutants and their siblings was prepared as above-mentioned, then mdm4 AS was visualized by PCR using CDNA template. AS detection primers used in this study are listed in Table S3.

\section{Western blot}

To obtain zebrafish protein, we distinguished 4 -dpf sart $3^{\text {smu471 }}$ mutants and their siblings based on the microcephaly and microphthalmia phenotype of the sart $3^{\text {smu }} 471$ mutant, then extracted total protein for western blot as previously described [76]. Mouse monoclonal antibody anti-p53 (1:200, ab77813, Abcam) $[77,78]$ and rabbit monoclonal antibody anti-GAPDH (1:1000, \#2118, Cell Signaling Technology, Danvers, MA, USA) were used as primary antibodies.

\section{FACS analysis}

The sart $3^{+/ s m u 471} ; \operatorname{Tg}(c d 41: e G F P)^{+/+}$zebrafish were intercrossed and 4-dpf sart $3^{\text {smu471 }}$ mutants as well their siblings were distinguished as mentioned above. The FACS experiment was performed as described previously [79]. As reported, cd41:eGFPlow labeled cells were recognized as HSPCs [46], and were, respectively, analyzed or sorted from sart3 ${ }^{\text {smu471 }}$ mutants and siblings using a MoFlo ${ }^{\mathrm{TM}}$ XDP (Beckman Coulter, Brea, CA, USA).

\section{Statistical analysis}

Data were recorded and analyzed using GraphPad Prism 7. Categorical variables were analyzed by Fisher's exact test. Comparisons between two groups were analyzed by two-tailed Student's $t$-test and nonparametric test (Mann-Whitney $U$ test), based on normal distribution data or not, respectively. Data were presented as means \pm standard deviation (SD). $P<0.05$ was considered statistically significant.

\section{DATA AVAILABILITY}

The RNA-seq data was submitted to the NCBI GEO repository with the accession number GSE182560.

\section{REFERENCES}

1. Jagannathan-Bogdan M, Zon LI. Hematopoiesis. Development 2013;140:2463-7.

2. Dzierzak E, de Pater E. Regulation of blood stem cell development. Curr Top Dev Biol. 2016;118:1-20.

3. Dzierzak E, Bigas A. Blood development: hematopoietic stem cell dependence and independence. Cell Stem Cell. 2018;22:639-51.

4. Avagyan S, Zon LI. Fish to learn: insights into blood development and blood disorders from zebrafish hematopoiesis. Hum Gene Ther. 2016;27:287-94.
5. Bao EL, Cheng AN, Sankaran VG. The genetics of human hematopoiesis and its disruption in disease. EMBO Mol Med. 2019;11:e10316.

6. Galloway JL, Zon LI. Ontogeny of hematopoiesis: examining the emergence of hematopoietic cells in the vertebrate embryo. Curr Top Dev Biol. 2003;53:139-58.

7. Palis J, Yoder MC. Yolk-sac hematopoiesis: the first blood cells of mouse and man. Exp Hematol. 2001;29:927-36.

8. Frame JM, McGrath KE, Palis J. Erythro-myeloid progenitors: "definitive" hematopoiesis in the conceptus prior to the emergence of hematopoietic stem cells. Blood Cells Mol Dis. 2013;51:220-5.

9. Dzierzak E, Speck NA. Of lineage and legacy: the development of mammalian hematopoietic stem cells. Nat Immunol. 2008;9:129-36.

10. Boisset JC, van Cappellen W, Andrieu-Soler C, Galjart N, Dzierzak E, Robin C. In vivo imaging of haematopoietic cells emerging from the mouse aortic endothelium. Nature 2010;464:116-20.

11. Ivanovs A, Rybtsov S, Welch L, Anderson RA, Turner ML, Medvinsky A. Highly potent human hematopoietic stem cells first emerge in the intraembryonic aortagonad-mesonephros region. J Exp Med. 2011;208:2417-27.

12. Cumano A, Godin I. Ontogeny of the hematopoietic system. Annu Rev Immunol. 2007;25:745-85.

13. Ciau-Uitz A, Monteiro R, Kirmizitas A, Patient R. Developmental hematopoiesis: ontogeny, genetic programming and conservation. Exp Hematol. 2014;42:669-83.

14. Chen AT, Zon LI. Zebrafish blood stem cells. J Cell Biochem. 2009;108:35-42.

15. Bertrand JY, Chi NC, Santoso B, Teng S, Stainier DY, Traver D. Haematopoietic stem cells derive directly from aortic endothelium during development. Nature 2010;464:108-11.

16. Kissa $K$, Herbomel P. Blood stem cells emerge from aortic endothelium by a novel type of cell transition. Nature 2010;464:112-5.

17. Murayama E, Kissa K, Zapata A, Mordelet E, Briolat V, Lin HF, et al. Tracing hematopoietic precursor migration to successive hematopoietic organs during zebrafish development. Immunity 2006;25:963-75.

18. Jin $\mathrm{H}, \mathrm{Xu} \mathrm{J}$, Wen Z. Migratory path of definitive hematopoietic stem/progenitor cells during zebrafish development. Blood 2007;109:5208-14.

19. Laurenti E, Gottgens B. From haematopoietic stem cells to complex differentiation landscapes. Nature 2018;553:418-26.

20. Cheng $\mathrm{H}$, Zheng $\mathrm{Z}$, Cheng $\mathrm{T}$. New paradigms on hematopoietic stem cell differentiation. Protein Cell. 2020;11:34-44.

21. Yoshida K, Sanada M, Shiraishi Y, Nowak D, Nagata Y, Yamamoto R, et al. Frequent pathway mutations of splicing machinery in myelodysplasia. Nature 2011;478:64-9.

22. Hahn CN, Venugopal P, Scott HS, Hiwase DK. Splice factor mutations and alternative splicing as drivers of hematopoietic malignancy. Immunol Rev. 2015;263:257-78.

23. Visconte $V, O$ Nakashima $M, J$ Rogers $H$. Mutations in splicing factor genes in myeloid malignancies: significance and impact on clinical features. Cancers. 2019;11:1844

24. Shirai $\mathrm{CL}$, Ley JN, White BS, Kim S, Tibbitts J, Shao J, et al. Mutant U2AF1 expression alters hematopoiesis and pre-mRNA splicing in vivo. Cancer Cell. 2015;27:631-43.

25. Obeng EA, Chappell RJ, Seiler M, Chen MC, Campagna DR, Schmidt PJ, et al. Physiologic expression of $\mathrm{Sf} 3 \mathrm{~b} 1(\mathrm{~K} 700 \mathrm{E})$ causes impaired erythropoiesis, aberrant splicing, and sensitivity to therapeutic spliceosome modulation. Cancer Cell. 2016;30:404-17.

26. Kim E, llagan JO, Liang Y, Daubner GM, Lee SC, Ramakrishnan A, et al. SRSF2 mutations contribute to myelodysplasia by mutant-specific effects on exon recognition. Cancer Cell. 2015;27:617-30.

27. Lee SC, Dvinge H, Kim E, Cho H, Micol JB, Chung YR, et al. Modulation of splicing catalysis for therapeutic targeting of leukemia with mutations in genes encoding spliceosomal proteins. Nat Med. 2016;22:672-8.

28. Seiler M, Yoshimi A, Darman R, Chan B, Keaney G, Thomas M, et al. H3B-8800, an orally available small-molecule splicing modulator, induces lethality in spliceosome-mutant cancers. Nat Med. 2018;24:497-504.

29. Wang E, Lu SX, Pastore A, Chen X, Imig J, Chun-Wei Lee S, et al. Targeting an RNA-binding protein network in acute myeloid leukemia. Cancer Cell. 2019;35:369-84 e7.

30. Gu J, Shimba S, Nomura N, Reddy R. Isolation and characterization of a new $110 \mathrm{kDa}$ human nuclear RNA-binding protein (p110nrb). Biochim Biophys Acta. 1998;1399:1-9.

31. Liu Y, Li J, Kim BO, Pace BS, He JJ. HIV-1 Tat protein-mediated transactivation of the HIV-1 long terminal repeat promoter is potentiated by a novel nuclear Tatinteracting protein of $110 \mathrm{kDa}$, Tip110. J Biol Chem. 2002;277:23854-63.

32. Bell M, Schreiner S, Damianov A, Reddy R, Bindereif A. p110, a novel human U6 snRNP protein and U4/U6 snRNP recycling factor. EMBO J. 2002;21:2724-35.

33. Raghunathan $\mathrm{PL}$, Guthrie C. A spliceosomal recycling factor that reanneals U4 and U6 small nuclear ribonucleoprotein particles. Science 1998;279:857-60.

34. Liu Y, Liu J, Wang Z, He JJ. Tip110 binding to U6 small nuclear RNA and its participation in pre-mRNA splicing. Cell Biosci. 2015;5:40. 
35. Liu Y, Kim BO, Kao C, Jung C, Dalton JT, He JJ. Tip110, the human immunodeficiency virus type 1 (HIV-1) Tat-interacting protein of $110 \mathrm{kDa}$ as a negative regulator of androgen receptor (AR) transcriptional activation. J Biol Chem. 2004;279:21766-73.

36. Liu Y, Timani K, Mantel C, Fan Y, Hangoc G, Cooper S, et al. TIP110/p110nrb/ SART3/p110 regulation of hematopoiesis through CMYC. Blood 2011;117:5643-51.

37. Timani KA, Liu Y, Fan Y, Mohammad KS, He JJ. Tip110 regulates the cross talk between $\mathrm{p} 53$ and hypoxia-inducible factor 1 alpha under hypoxia and promotes survival of cancer cells. Mol Cell Biol. 2015;35:2254-64.

38. Ito M, Shichijo S, Miyagi Y, Kobayashi T, Tsuda N, Yamada A, et al. Identification of SART3-derived peptides capable of inducing HLA-A2-restricted and tumorspecific CTLs in cancer patients with different HLA-A2 subtypes. Int J Cancer. 2000;88:633-9.

39. Miyagi $Y$, Imai N, Sasatomi T, Yamada A, Mine T, Katagiri $K$, et al. Induction of cellular immune responses to tumor cells and peptides in colorectal cancer patients by vaccination with SART3 peptides. Clin Cancer Res. 2001;7:3950-62.

40. Noguchi M, Koga N, Moriya F, Suekane S, Yutani S, Yamada A, et al. Survival analysis of multiple peptide vaccination for the selection of correlated peptides in urological cancers. Cancer Sci. 2018;109:2660-9.

41. Liu Y, Lee MR, Timani K, He JJ, Broxmeyer HE. Tip110 maintains expression of pluripotent factors in and pluripotency of human embryonic stem cells. Stem Cells Dev. 2012;21:829-33.

42. Liu Y, Timani K, Ou X, Broxmeyer HE, He JJ. C-MYC controlled TIP110 protein expression regulates OCT4 mRNA splicing in human embryonic stem cells. Stem Cells Dev. 2013;22:689-94.

43. Trede NS, Medenbach J, Damianov A, Hung LH, Weber GJ, Paw BH, et al. Network of coregulated spliceosome components revealed by zebrafish mutant in recycling factor p110. Proc Natl Acad Sci USA. 2007;104:6608-13.

44. Liu Y, Huang X, Timani KA, Broxmeyer HE, He JJ. MicroRNA-124 targets Tip110 expression and regulates hematopoiesis. Stem Cells Dev. 2015;24:2009-17.

45. Wang K, Huang Z, Zhao L, Liu W, Chen X, Meng P, et al. Large-scale forward genetic screening analysis of development of hematopoiesis in zebrafish. J Genet Genomics. 2012;39:473-80.

46. Kissa K, Murayama E, Zapata A, Cortes A, Perret E, Machu C, et al. Live imaging of emerging hematopoietic stem cells and early thymus colonization. Blood 2008;111:1147-56.

47. Xue Y, Liu D, Cui G, Ding Y, Ai D, Gao S, et al. A 3D atlas of hematopoietic stem and progenitor cell expansion by multi-dimensional RNA-Seq analysis. Cell Rep. 2019;27:1567-78 e5.

48. Pant V, Quintas-Cardama A, Lozano G. The p53 pathway in hematopoiesis: lessons from mouse models, implications for humans. Blood 2012;120:5118-27.

49. Berghmans S, Murphey RD, Wienholds E, Neuberg D, Kutok JL, Fletcher CD, et al. tp53 mutant zebrafish develop malignant peripheral nerve sheath tumors. Proc Natl Acad Sci USA. 2005;102:407-12.

50. Medenbach J, Schreiner S, Liu S, Luhrmann R, Bindereif A. Human U4/U6 snRNP recycling factor $\mathrm{p} 110$ : mutational analysis reveals the function of the tetratricopeptide repeat domain in recycling. Mol Cell Biol. 2004;24:7392-401.

51. Zhou Y, Zhou B, Pache L, Chang M, Khodabakhshi AH, Tanaseichuk O, et al. Metascape provides a biologist-oriented resource for the analysis of systemslevel datasets. Nat Commun. 2019;10:1523.

52. Rallapalli R, Strachan G, Cho B, Mercer WE, Hall DJ. A novel MDMX transcript expressed in a variety of transformed cell lines encodes a truncated protein with potent p53 repressive activity. J Biol Chem. 1999;274:8299-308.

53. Shvarts A, Steegenga WT, Riteco N, van Laar T, Dekker $P$, Bazuine $M$, et al. MDMX a novel p53-binding protein with some functional properties of MDM2. EMBO J. 1996;15:5349-57.

54. Linares LK, Hengstermann A, Ciechanover A, Muller S, Scheffner M. HdmX stimulates $\mathrm{Hdm} 2$-mediated ubiquitination and degradation of $\mathrm{p} 53$. Proc Natl Acad Sci USA. 2003;100:12009-14.

55. Deffie A, Wu H, Reinke V, Lozano $G$. The tumor suppressor p53 regulates its own transcription. Mol Cell Biol. 1993;13:3415-23.

56. Kastan MB, Canman CE, Leonard CJ. P53, cell cycle control and apoptosis: implications for cancer. Cancer Metastasis Rev. 1995;14:3-15.

57. Chen J. The cell-cycle arrest and apoptotic functions of p53 in tumor initiation and progression. Cold Spring Harb Perspect Med. 2016;6:a026104.

58. Dumble M, Moore L, Chambers SM, Geiger H, Van Zant G, Goodell MA, et al. The impact of altered p53 dosage on hematopoietic stem cell dynamics during aging. Blood 2007;109:1736-42.

59. Liu Y, Elf SE, Miyata Y, Sashida G, Liu Y, Huang G, et al. p53 regulates hematopoietic stem cell quiescence. Cell Stem Cell. 2009;4:37-48.

60. Allende-Vega N, Dayal S, Agarwala U, Sparks A, Bourdon JC, Saville MK. p53 is activated in response to disruption of the pre-mRNA splicing machinery. Oncogene 2013;32:1-14.
61. Lei L, Yan SY, Yang R, Chen JY, Li Y, Bu Y, et al. Spliceosomal protein eftud2 mutation leads to p53-dependent apoptosis in zebrafish neural progenitors. Nucleic Acids Res. 2017;45:3422-36.

62. Yu S, Jiang T, Jia D, Han Y, Liu F, Huang Y, et al. BCAS2 is essential for hematopoietic stem and progenitor cell maintenance during zebrafish embryogenesis. Blood 2019;133:805-15.

63. Dewaele M, Tabaglio T, Willekens K, Bezzi M, Teo SX, Low DH, et al. Antisense oligonucleotide-mediated MDM4 exon 6 skipping impairs tumor growth. J Clin Invest. 2016;126:68-84

64. Bezzi M, Teo SX, Muller J, Mok WC, Sahu SK, Vardy LA, et al. Regulation of constitutive and alternative splicing by PRMT5 reveals a role for Mdm4 pre-mRNA in sensing defects in the spliceosomal machinery. Genes Dev. 2013;27:1903-16.

65. Timani KA, Gyorffy B, Liu Y, Mohammad KS, He JJ. Tip110/SART3 regulates IL-8 expression and predicts the clinical outcomes in melanoma. Mol Cancer. 2018;17:124.

66. Westerfield M. The zebrafish book: a guide for the laboratory use of zebrafish (Brachydanio rerio). Eugene, OR: M. Westerfield; 1993.

67. Lin HF, Traver D, Zhu H, Dooley K, Paw BH, Zon LI, et al. Analysis of thrombocyte development in CD41-GFP transgenic zebrafish. Blood 2005;106:3803-10.

68. Zhou Y, Zon LI. The zon laboratory guide to positional cloning in zebrafish. Methods Cell Biol. 2011;104:287-309.

69. Chang N, Sun C, Gao L, Zhu D, Xu X, Zhu X, et al. Genome editing with RNAguided Cas9 nuclease in zebrafish embryos. Cell Res. 2013;23:465-72.

70. Langheinrich U, Hennen E, Stott G, Vacun G. Zebrafish as a model organism for the identification and characterization of drugs and genes affecting p53 signaling. Curr Biol. 2002;12:2023-8.

71. Thisse $C$, Thisse B. High-resolution in situ hybridization to whole-mount zebrafish embryos. Nat Protoc. 2008;3:59-69.

72. Barresi MJ, Stickney HL, Devoto SH. The zebrafish slow-muscle-omitted gene product is required for Hedgehog signal transduction and the development of slow muscle identity. Development 2000;127:2189-99.

73. Du L, Xu J, Li X, Ma N, Liu Y, Peng J, et al. Rumba and Haus3 are essential factors for the maintenance of hematopoietic stem/progenitor cells during zebrafish hematopoiesis. Development 2011;138:619-29.

74. Li X, Lan Y, Xu J, Zhang W, Wen Z. SUMO1-activating enzyme subunit 1 is essential for the survival of hematopoietic stem/progenitor cells in zebrafish. Development 2012;139:4321-9.

75. Shen S, Park JW, Lu ZX, Lin L, Henry MD, Wu YN, et al. rMATS: robust and flexible detection of differential alternative splicing from replicate RNA-Seq data. Proc Natl Acad Sci USA. 2014;111:E5593-601.

76. Wen Z, Zhong Z, Darnell JE Jr. Maximal activation of transcription by Stat 1 and Stat3 requires both tyrosine and serine phosphorylation. Cell. 1995;82:241-50.

77. Shi H, Tao T, Huang D, Ou Z, Chen J, Peng J. A naturally occurring 4-bp deletion in the intron 4 of p53 creates a spectrum of novel p53 isoforms with anti-apoptosis function. Nucleic Acids Res. 2015;43:1035-43.

78. McElderry J, Carrington B, Bishop K, Kim E, Pei W, Chen Z, et al. Splicing factor DHX15 affects tp53 and mdm2 expression via alternate splicing and promoter usage. Hum Mol Genet. 2019;28:4173-85.

79. Manoli M, Driever W. Fluorescence-activated cell sorting (FACS) of fluorescently tagged cells from zebrafish larvae for RNA isolation. Cold Spring Harb Protoc. 2012;2012:pdb-prot069633.

\section{ACKNOWLEDGEMENTS}

We thank Dr. Bo Zhang and Dr. Jingwei Xiong for sharing CRISPR/Cas9-related material (gRNA-pMD19-T) and protocols. We thank Dr. Robert I. Handin and Dr. Leonard I. Zon for sharing us $T g(c d 41: e G F P)$ and $p 53^{M 214 K}$ fish lines. We thank Dr. Kun Wang, Mr. Xiaohui Chen, and Ms. Li Song for the animal maintenance and technique assistance.

\section{AUTHOR CONTRIBUTIONS}

Y Zhang supervised this study; ZW and WZ initiated the mutant screening; $Y$ Zhao performed most experiments; $Y$ Zhang, $Y$ Zhao, and MW analyzed the data and wrote the manuscript; JL, JX, and ZH provided technique advice and discussion; and PM and $J C$ helped with the mutant strain maintaining.

\section{FUNDING}

This work was supported by the National Key Research and Development Program of China (2018YFA0800200 and 2018YFA0801000), the National Natural Science Foundation of China (31922023), and Guangdong Province Universities and Colleges Pearl River Scholar Funded Scheme (2019). 
12

\section{COMPETING INTERESTS}

The authors declare no competing interests.

\section{ETHICS STATEMENT}

The zebrafish study was reviewed and approved by the animal research advisory committee of South China University of Technology.

\section{ADDITIONAL INFORMATION}

Supplementary information The online version contains supplementary material available at https://doi.org/10.1038/s41419-021-04215-4.

Correspondence and requests for materials should be addressed to Wenqing Zhang or Yiyue Zhang.

Reprints and permission information is available at http://www.nature.com/ reprints
Publisher's note Springer Nature remains neutral with regard to jurisdictional claims in published maps and institutional affiliations. c. Attribution 4.0 International License, which permits use, sharing, adaptation, distribution and reproduction in any medium or format, as long as you give appropriate credit to the original author(s) and the source, provide a link to the Creative Commons license, and indicate if changes were made. The images or other third party material in this article are included in the article's Creative Commons license, unless indicated otherwise in a credit line to the material. If material is not included in the article's Creative Commons license and your intended use is not permitted by statutory regulation or exceeds the permitted use, you will need to obtain permission directly from the copyright holder. To view a copy of this license, visit http://creativecommons. org/licenses/by/4.0/.

(c) The Author(s) 2021 